Rapid Communications

\title{
Formation of Minimal Third Phase in Ionic Liquid Extraction System with Trioctylphosphine Oxide and Its Possible Application to Extraction Concentration
}

\author{
Mizuki Toita, Kotaro Morita, and Naoki Hirayama ${ }^{\dagger}$ \\ Department of Chemistry, Faculty of Science, Toho University, 2-2-1 Miyama, Funabashi 274-8510, Japan
}

\begin{abstract}
The third-phase formation behavior in ionic liquid (IL) extraction system using trioctylphosphine oxide (TOPO) was investigated. In the use of a relatively less-lipophilic IL, such as 1-butyl-3-methylimidazolium bis(trifluoromethanesulfonyl)imide $\left(\mathrm{C}_{4} \operatorname{mimTf}_{2} \mathrm{~N}\right)$, the third phase was formed between the aqueous phase and the IL phase. The third phase seems to have a relatively high lipophilicity compared to the IL phase. The main components of the third phase were suggested as being $\left(\mathrm{H}_{3} \mathrm{O}\right) \mathrm{TOPO}^{+}$, IL anion $\left(\mathrm{Tf}_{2} \mathrm{~N}^{-}\right)$, IL cation $\left(\mathrm{C}_{4} \mathrm{mim}^{+}\right)$and free TOPO. In addition, the third phase showed an extraction concentration ability for the $\mathrm{Fe}(\mathrm{III})$-thiocyanato complex.
\end{abstract}

Keywords Ionic liquids, extraction, third phase, concentration

(Received August 1, 2018; Accepted August 3, 2018; Advance Publication Released Online by J-STAGE August 17, 2018)

Ionic liquids (ILs) have attracted attention as novel fluid media and hydrophobic ILs, including 1-alkyl-3-methylimidazolium hexafluorophosphates $\left(\mathrm{C}_{\mathrm{n}} \mathrm{mimPF}_{6}\right)$ and bis(trifluoromethanesulfonyl)imides $\left(\mathrm{C}_{\mathrm{n}} \operatorname{mimTf}_{2} \mathrm{~N}\right)$, have often been used as an extraction solvent in solvent extraction for metals. ${ }^{1-6}$ Trioctylphosphine oxide (TOPO) is a well-known lipophilic monodentate Lewis base, and is often used in traditional metal extraction as an extractant or a synergistic agent. Also in the IL extraction, the possible use of TOPO has been energetically investigated..$^{7-14}$ However, Liu et al. made mention in their literature ${ }^{15}$ that the use of TOPO on the IL extraction resulted in the formation of an "undesirable" third phase.

In the traditional metal extraction system using organic solvents, third-phase formation is a well-known problematic phenomenon. ${ }^{16}$ Generally, the co-use of a nonpolar organic solvent (ex. dodecane), a neutral Lewis base (ex. tributyl phosphate) and a relatively high concentration of a mineral acid (ex. nitric acid) often results in the formation, and the formed third phase is relatively less-lipophilic. On the contrary, ILs are relatively high-polar solvents and third-phase formation mechanism in the IL system seems to be different from that in the traditional one. In this communication, we discuss on the third-phase formation behavior on using TOPO in the IL $\left(\mathrm{C}_{\mathrm{n}} \operatorname{mimTf}_{2} \mathrm{~N}\right)$ extraction system, and possible use of the thirdphase formation to extraction concentration.

\section{Experimental}

Chemicals were of reagent-grade and were used without further purification. Four ILs [1-ethyl-3-methylimidazolium bis(trifluoromethanesulfonyl)imide $\left(\mathrm{C}_{2}\right.$ mimTf $\left._{2} \mathrm{~N}\right)$, 1-butyl-3- methylimidazolium bis(trifluoromethanesulfonyl)imide $\left(\mathrm{C}_{4} \operatorname{mimTf}_{2} \mathrm{~N}\right)$, 1-hexyl-3methylimidazolium bis(trifluoromethanesulfonyl)imide $\left(\mathrm{C}_{6} \operatorname{mimTf}_{2} \mathrm{~N}\right)$

† To whom correspondence should be addressed.

E-mail: hirayama@sci.toho-u.ac.jp and 1-methyl-3-octylimidazolium bis(trifluoromethanesulfonyl)imide $\left(\mathrm{C}_{8} \operatorname{mimTf}_{2} \mathrm{~N}\right)$ ] were synthesized according to a reported procedure. ${ }^{17,18}$ High-purity water prepared with using a Direct-Q water purification system (Millipore) was used throughout.

A third-phase formation experiment was performed as follows. In a centrifuge tube, $1.0 \mathrm{~cm}^{3}$ of an IL phase containing $1.0 \times$ $10^{-1} \mathrm{~mol} \mathrm{dm}^{-3}$ of TOPO and $5.0 \mathrm{~cm}^{3}$ of an aqueous phase containing $1.0 \times 10^{-1} \mathrm{~mol} \mathrm{dm}^{-3}$ of $(\mathrm{H}, \mathrm{K}) \mathrm{NO}_{3}$ were shaken mechanically at $25 \pm 1^{\circ} \mathrm{C}$ for $30 \mathrm{~min}$. After centrifugation, the third-phase formation behavior was observed and the $\mathrm{pH}$ in the aqueous phase was measured. If needed, the volume of the third phase was measured after dissolving the phase into cyclohexane, putting the dissolved one into a calibrated glass tube and evaporating the cyclohexane under reduced pressure.

A metal extraction study was performed as follows. In a centrifuge tube, $1.0 \mathrm{~cm}^{3}$ of an IL phase containing $1.0 \times 10^{-1}$ mol dm${ }^{-3}$ of TOPO and $5.0 \mathrm{~cm}^{3}$ of an aqueous phase containing $4.5 \mu \mathrm{g} \mathrm{cm}^{-3}$ of $\mathrm{Fe}(\mathrm{III}), 1.0 \times 10^{-1} \mathrm{~mol} \mathrm{dm}^{-3}$ of $(\mathrm{H}, \mathrm{K}) \mathrm{NO}_{3}$ and $1.0 \times 10^{-2} \mathrm{~mol} \mathrm{dm}^{-3}$ of $\mathrm{KSCN}$ were shaken mechanically at $25 \pm 1{ }^{\circ} \mathrm{C}$ for $30 \mathrm{~min}$. After phase separation by centrifugation, the $\mathrm{pH}$ in the aqueous phase was measured. The Fe concentration remaining in the aqueous phase was determined by flame atomic absorption spectrophotometry. That extracted into the IL phase was determined similarly after back-extraction into a 10 -fold volume of $6 \mathrm{~mol} \mathrm{dm}^{-3} \mathrm{HNO}_{3}$ and the extractability into the IL phase $\left(\% E_{\mathrm{IL}}\right)$ was calculated. The extractability into the third phase $\left(\% E_{3 \mathrm{rd}}\right)$ was calculated based on the mass balance.

\section{Results and Discussion}

At first, we investigated whether the third phase is formed or not with using the four ILs. A small volume of the colorless third phase was formed with the use of less-lipophilic $\mathrm{C}_{2} \operatorname{mimTf}_{2} \mathrm{~N}$ and $\mathrm{C}_{4} \operatorname{mimTf}_{2} \mathrm{~N}$, whereas the use of more-lipophilic $\mathrm{C}_{6} \operatorname{mimTf}_{2} \mathrm{~N}$ and $\mathrm{C}_{8} \operatorname{mimTf}_{2} \mathrm{~N}$ resulted in no third-phase formation. Figure 1 shows a typical photograph at aqueous phase $\mathrm{pH} 3.0$, in which 


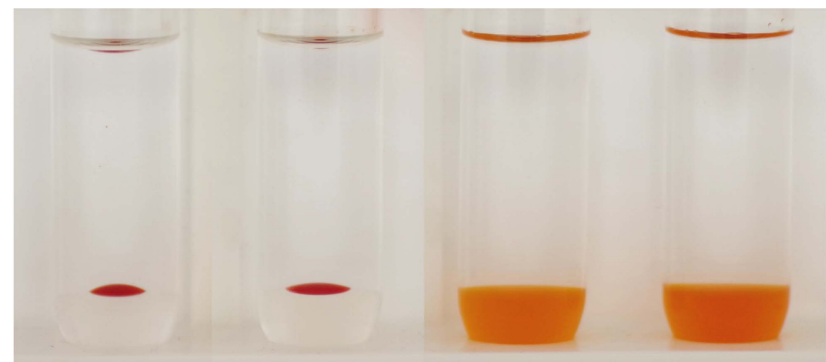

A

B

C

D

Fig. 1 Third-phase formation behavior upon adding TOPO in the IL extraction system. IL phase $\left(1.0 \mathrm{~cm}^{3}\right): \mathrm{A}, \mathrm{C}_{2} \operatorname{mimTf}_{2} \mathrm{~N} ; \mathrm{B}, \mathrm{C}_{4} \operatorname{mimTf}_{2} \mathrm{~N}$; $\mathrm{C}, \mathrm{C}_{6} \operatorname{mimTf}_{2} \mathrm{~N} ; \mathrm{D}, \mathrm{C}_{8} \operatorname{mimTf}_{2} \mathrm{~N}$. Aqueous phase $\left(5.0 \mathrm{~cm}^{3}\right): 1.0 \times 10^{-1}$ mol dm${ }^{-3}$ of $\mathrm{KNO}_{3}, \mathrm{pH}$ 3.0. Initial TOPO concentration in the IL phase: $1.0 \times 10^{-1} \mathrm{~mol} \mathrm{dm}^{-3}$. (Fe(III)-thiocyanato complex was added.)

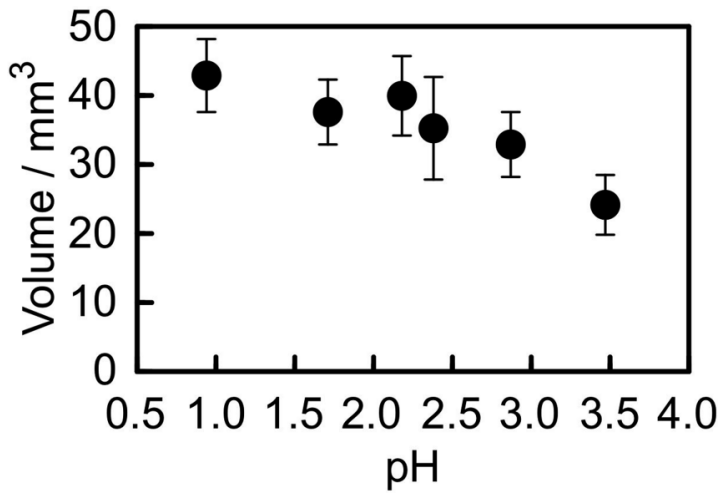

Fig. 2 Relationship between the volume of the formed third phase and the aqueous phase $\mathrm{pH}$ in the $\mathrm{C}_{4} \operatorname{mimTf}_{2} \mathrm{~N}$-TOPO system. IL phase $\left(1.0 \mathrm{~cm}^{3}\right): 1.0 \times 10^{-1} \mathrm{~mol} \mathrm{dm}{ }^{-3}$ TOPO. Aqueous phase $\left(1.0 \mathrm{~cm}^{3}\right)$ : $1.0 \times 10^{-1} \mathrm{~mol} \mathrm{dm}^{-3}$ of $(\mathrm{H}, \mathrm{K}) \mathrm{NO}_{3}$.

the $\mathrm{Fe}$ (III)-thiocyanato complex was added to the system with consideration for the visibility of the third phase. The result is in accordance with the previous report, ${ }^{15}$ and it was suggested that the third phase has a relatively high lipophilicity compared to the IL phase. In addition, it was confirmed that the density of the third phase is between water and the IL. In this study, further experiments were performed with using $\mathrm{C}_{4} \operatorname{mimTf}_{2} \mathrm{~N}$ as an IL.

Next, the volume of the formed third phase in the $\mathrm{C}_{4} \operatorname{mimTf}_{2} \mathrm{~N}$ TOPO system was evaluated. At $\mathrm{pH}>3$, the phase decreased in size and disappeared based on visual observation, suggesting that an acidic condition is needed to form the third phase. Using the fact that the third phase is soluble into cyclohexane, the volume of the third phase was measured at $\mathrm{pH} 0.9-3.5$. (The third phase is so viscous that its volume cannot be directly measured by pipetting it.) The determined volume is summarized in Fig. 2. Although the volume decreased slightly with the increase in the aqueous phase $\mathrm{pH}$, the volume was estimated as being $c a .40 \mathrm{~mm}^{3}$ at $1<\mathrm{pH}<3$. In addition, a decrease in the TOPO concentration resulted in a noticeable decrease in the third-phase volume, and the phase disappeared almost completely on $1.0 \times 10^{-2} \mathrm{~mol} \mathrm{dm}^{-3} \mathrm{TOPO}$. From these results, it was suggested that the $\left(\mathrm{H}_{3} \mathrm{O}\right) \mathrm{TOPO}^{+}$complex is an important component for the third phase.

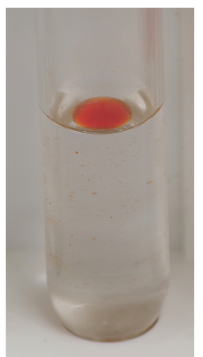

A

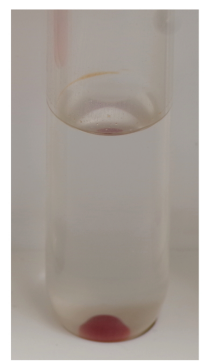

B

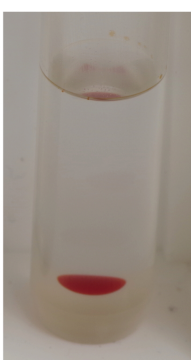

C
Fig. 3 Transition of phase separation behavior. A: $5.0 \mathrm{~cm}^{3}$ of aqueous phase $\left(1.0 \times 10^{-1} \mathrm{~mol} \mathrm{dm}^{-3}\right.$ of $\left.\mathrm{KNO}_{3}, \mathrm{pH} 3.0\right)+20 \mathrm{~mm}^{3}$ of $\left(\mathrm{H}_{3} \mathrm{O}\right) \mathrm{TOPO}^{+} \cdot \mathrm{Tf}_{2} \mathrm{~N}^{-}, \mathrm{B}: \mathrm{A}+40 \mathrm{~mm}^{3}$ of $\mathrm{C}_{4} \operatorname{mimTf}_{2} \mathrm{~N}, \mathrm{C}: \mathrm{A}+1.0 \mathrm{~cm}^{3}$ of $\mathrm{C}_{4} \operatorname{mimTf}_{2} \mathrm{~N}$. ( $\mathrm{Fe}(\mathrm{III})$-thiocyanato complex was added.)

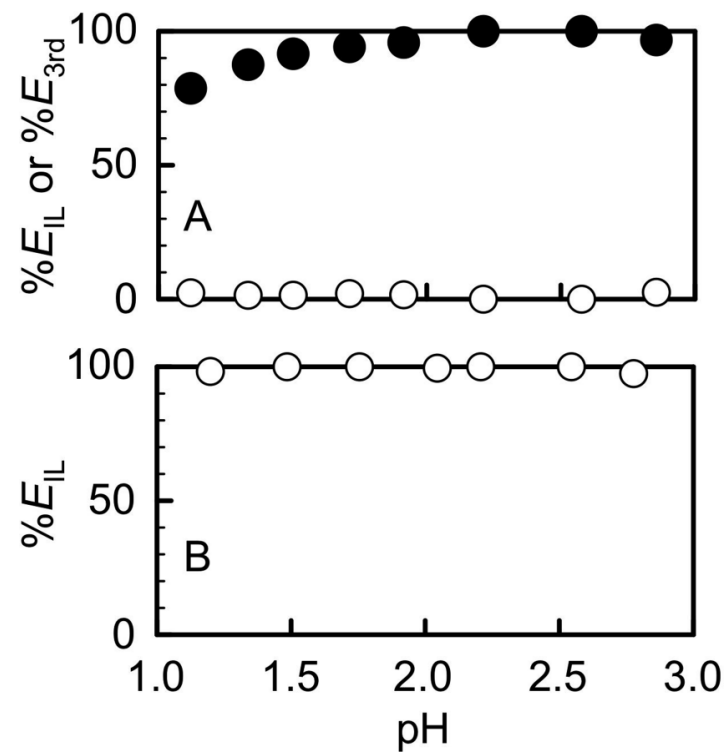

Fig. 4 Aqueous phase pH dependency of $\% E_{\mathrm{IL}}(\bigcirc)$ and $\% E_{3 \mathrm{rd}}(\mathbf{O})$ in the $\mathrm{C}_{4}$ mimTf $_{2} \mathrm{~N}$-TOPO system (A) and the $\mathrm{C}_{6}$ mimTf $_{2} \mathrm{~N}$-TOPO system (B). IL phase $\left(1.0 \mathrm{~cm}^{3}\right): 1.0 \times 10^{-1} \mathrm{~mol} \mathrm{dm}^{-3}$ TOPO. Aqueous phase $\left(1.0 \mathrm{~cm}^{3}\right): 1.0 \times 10^{-1} \mathrm{~mol} \mathrm{dm}^{-3}$ of $(\mathrm{H}, \mathrm{K}) \mathrm{NO}_{3}$ and $1.0 \times 10^{-2} \mathrm{~mol} \mathrm{dm}^{-3}$ of KSCN.

To evaluate other components in the third phase, the following phase separation experiment was performed. The addition of TOPO to a $0.1 \mathrm{~mol} \mathrm{dm}^{-3} \mathrm{HTf}_{2} \mathrm{~N}$ aqueous solution resulted in forming a water-immiscible colorless liquid phase upon the solution. It was estimated that this liquid phase consisted mainly of $\left(\mathrm{H}_{3} \mathrm{O}\right) \mathrm{TOPO}^{+} \cdot \mathrm{Tf}_{2} \mathrm{~N}^{-}$, and the density of the phase was less than water. After pipetting $20 \mathrm{~mm}^{3}$ of the liquid phase and adding it to $5.0 \mathrm{~cm}^{3}$ of an aqueous solution (pH 3.0) (Fig. 3A), $40 \mathrm{~mm}^{3}$ of $\mathrm{C}_{4} \operatorname{mimTf}_{2} \mathrm{~N}$ was added. The liquid phase became unified with the IL phase and sank under the aqueous phase (Fig. 3B). A further addition of $\mathrm{C}_{4} \operatorname{mimTf}_{2} \mathrm{~N}$ resulted in re-forming a new phase between the aqueous phase and the IL phase (Fig. 3C). From the result, it was suggested that not only $\mathrm{Tf}_{2} \mathrm{~N}^{-}$(IL anion) but also $\mathrm{C}_{4} \mathrm{mim}^{+}$(IL cation) are important components for the third phase formed in the $\mathrm{C}_{4} \operatorname{mimTf}_{2} \mathrm{~N}$ TOPO extraction system.

Because of the relatively lipophilic nature, it was expected that the third phase contains a significant amount of TOPO not 
only as $\left(\mathrm{H}_{3} \mathrm{O}\right) \mathrm{TOPO}^{+}$but also as free TOPO. This hypothesis can be verified by studying metal extraction into the third phase. Thus, the extraction behavior of the Fe(III)-thiocyanato complex into the third phase was investigated. Figure 4 shows $\% E_{\mathrm{IL}}$ and $\% E_{3 \mathrm{rd}}$ for $\mathrm{Fe}(\mathrm{III})$ in the $\mathrm{C}_{4} \mathrm{mimTf}_{2} \mathrm{~N}$-TOPO system coexisting $1.0 \times 10^{-2} \mathrm{~mol} \mathrm{dm}^{-3}$ of thiocyanate in the aqueous phase as a function of the aqueous phase $\mathrm{pH}$. For a comparison, $\% E_{\mathrm{IL}}$ for $\mathrm{Fe}$ (III) in the $\mathrm{C}_{6} \operatorname{mimTf}_{2} \mathrm{~N}-\mathrm{TOPO}$ system is also shown in the figure. In the $\mathrm{C}_{4} \mathrm{mimTf}_{2} \mathrm{~N}$-TOPO system, $\mathrm{Fe}(\mathrm{III})$ was quantitatively extracted into the third phase with a reddish coloration, whereas the use of the $\mathrm{C}_{6} \mathrm{mimTf}_{2} \mathrm{~N}-\mathrm{TOPO}$ system resulted in the extraction of $\mathrm{Fe}(\mathrm{III})$ into the $\mathrm{IL}\left(\mathrm{C}_{6} \mathrm{mimTf}_{2} \mathrm{~N}\right)$ phase. Moreover, the absence of TOPO resulted in scarce $\mathrm{Fe}(\mathrm{III})$ extraction in both of the systems, which is in agreement with a previous study using the $\mathrm{C}_{4} \mathrm{mimPF}_{6}$ system. ${ }^{19}$ From these results, it was suggested that the formed third phase in the $\mathrm{C}_{4} \operatorname{mimTf}_{2} \mathrm{~N}$-TOPO has a certain content of free TOPO, and that the extracted $\mathrm{Fe}(\mathrm{III})$ species is the $\mathrm{Fe}(\mathrm{III})-\mathrm{SCN}^{-}-\mathrm{TOPO}$ ternary (and probably neutral) complex. In addition, Fe(III) in the aqueous phase was calculationally $c a$. 100 -fold concentrated by extraction into the third phase.

In conclusion, it was confirmed that third phase is formed in the $\mathrm{C}_{2}$ mimTf $_{2} \mathrm{~N}$-TOPO and $\mathrm{C}_{4}$ mimTf $_{2} \mathrm{~N}$-TOPO extraction systems under an acidic condition. In the latter system, $c a .40 \mathrm{~mm}^{3}$ of the third phase was formed from $1.0 \mathrm{~cm}^{3}$ of the $\mathrm{C}_{4} \operatorname{mimTf}_{2} \mathrm{~N}$ containing $1.0 \times 10^{-1} \mathrm{~mol} \mathrm{dm}{ }^{-3}$ of TOPO and $5.0 \mathrm{~cm}^{3}$ of the aqueous phase at $1<\mathrm{pH}<3$. The main components of the third phase were suggested as being $\left(\mathrm{H}_{3} \mathrm{O}\right) \mathrm{TOPO}^{+}$, IL anion $\left(\mathrm{Tf}_{2} \mathrm{~N}^{-}\right)$, IL cation and free TOPO. Since its extraction ability for the Fe(III)-thiocyanato complex, furthermore, it was found that the third-phase formation is not always unfavorable for extraction separation but that the third phase can be used as an extraction concentration medium.

\section{Acknowledgements}

This study was financially supported in part by JSPS KAKENHI Grant No. JP26410162 and No. JP18K05183 from the Japan Society for the Promotion of Science.

\section{References}

1. N. Hirayama, Solvent Extr. Res. Dev., Jpn., 2011, 18, 1, and references therein.

2. N. Hirayama, Bunseki, 2014, 177 (in Japanese), and references therein.

3. M. Sakato and N. Hirayama, Anal. Sci., 2014, 30, 783.

4. K. Chayama, Y. Sano, and S. Iwatsuki, Anal. Sci., 2015, 31, 1115.

5. A. Eguchi, K. Morita, and N. Hirayama, Anal. Sci., 2017, 33, 1447.

6. M. Atanassova, H. Okamura, A. Eguchi, Y. Ueda, T. Sugita, and K. Shimojo, Anal. Sci., 2018, 34, 973.

7. F. Kubota, Y. Shimobori, Y. Koyanagi, K. Nakashima, K. Shimojo, N. Kamiya, and M. Goto, Solvent Extr. Res. Dev., Jpn., 2009, 16, 151.

8. T. Takata and N. Hirayama, Anal. Sci., 2009, 25, 1269.

9. F. Yang, F. Kubota, N. Kamiya, and M. Goto, Solvent Extr. Res. Dev., Jpn., 2013, 20, 225.

10. Z. Zhao, Y. Baba, F. Kubota, N. Kamiya, and M. Goto, J. Chem. Eng. Jpn., 2014, 47, 656.

11. P. K. Mohapatra, D. R. Raut, and A. Sengupta, Sep. Purif. Technol., 2014, 133, 69.

12. H. Okamura, H. Takagi, T. Isomura, K. Morita, H. Nagatani, and H. Imura, Anal. Sci., 2014, 30, 323.

13. R. B. Gujar, A. Sengupta, M. S. Murali, and P. K. Mohapatra, Sep. Sci. Technol., 2017, 52, 2318.

14. M. Hatakeyama, Y. Nishiyama, H. Nagatani, H. Okamura, and H. Imura, Solvent Extr. Res. Dev., Jpn., 2018, 25, 79.

15. H.-W. Liu, X.-H. Shen, and Q.-D. Chen, Acta Phys. Chim. Sin., 2015, 31, 843 (in Chinese).

16. R. Chiarizia, M. P. Jensen, M. Borkowski, J. R. Ferraro, P. Thiyagarajan, and K. C. Littrell, Solv. Extr. Ion Exch., 2003, $21,1$.

17. S. V. Dzyuba and R. A. Bartsch, ChemPhysChem, 2002, 3, 161.

18. A. K. Burrell, R. E. Del Sesto, S. N. Baker, T. M. McCleskeya, and G. A. Baker, Green Chem., 2007, 9, 449.

19. A. E. Visser, R. P. Swatloski, S. T. Griffin, D. H. Hartman, and R. D. Rogers, Sep. Sci. Technol., 2001, 36, 785. 